\title{
Sepsis por Pseudomona como forma de debut de inmunodeficiencia primaria en un niño
}

\author{
Sepsis due to Pseudomona as a debut of a primary immunodeficiency in a child
}

\author{
Lic. M. Cristina Vera Sáez-Benito ${ }^{a}$, Lic. Marta López Úbeda ${ }^{a}$, Dra. Paula Madurga Revilla ${ }^{a}$ \\ Dr. Antonio de Arriba Muñoz ${ }^{a}$ Dra. Matilde Bustillo Alonso y Dra. Carmen Rodríguez-Vigil Iturrate ${ }^{a}$
}

\section{RESUMEN}

La agammaglobulinemia ligada al $\mathrm{X}$ es una inmunodeficiencia humoral primaria, recesiva y ligada al cromosoma $X$, en la que existe una disminución marcada de linfocitos B maduros, hipo-/agammaglobulinemia y escasa respuesta humoral a las inmunizaciones, debido a mutaciones en el brazo largo del cromosoma X.

Se caracteriza por infecciones graves, recurrentes y difíciles de tratar, que ocurren, generalmente, a partir de los 6 meses. El único signo de alarma, no siempre presente, es la ausencia o disminución del tamaño de las amígdalas y los ganglios linfáticos.

El tratamiento de elección es el sustitutivo con inmunoglobulina $\mathrm{G}$ intravenosa para mantener niveles séricos por encima de $500-700 \mathrm{mg} / \mathrm{dl} \mathrm{y} \mathrm{el} \mathrm{control} \mathrm{de} \mathrm{las} \mathrm{infecciones,} \mathrm{lo} \mathrm{que} \mathrm{permite}$ que estos pacientes hagan sus tareas habituales.

Se presenta un niño de 2 años sin antecedentes personales ni familiares relevantes diagnosticado con agammaglobulinemia ligada al $X$ tras una sepsis por $P$. aeruginosa. Tuvo una evolución clínica adecuada sin nuevos episodios infecciosos importantes tras el inicio del tratamiento sustitutivo con inmunoglobulina G intravenosa mensual.

Palabrasclave:agammaglobulinemialigadaal X, inmunoglobulinas, ectima, gangrena, P. aeruginosa.

\section{ABSTRACT}

$\mathrm{X}$-linked agammaglobulinemia is a primary humoral immunodeficiency. It is a recessive X-linked disorder characterized by low or absent circulating mature B cells, hypo/agammaglobulinemia and no humoral response to immunizations due to mutations along chromosome $\mathrm{X}$.

It is characterized by severe, recurrent and difficult treatment infections. It is diagnosed in the first 6 months of life in children; the only sign of alarm is the absent or decreased size of tonsils and lymph nodes, but it is not always present.

The main cornerstones of treatment are immunoglobulin replacement therapy to maintain serum levels above 500-700 $\mathrm{mg} / \mathrm{dl}$ and infection control; this allows these patients to do their day-to-day activities.

a. Hospital Universitario Miguel Servet, Zaragoza, España.

Correspondencia:

Lic. M. Cristina Vera Sáez-Benito, veramcristina@gmail.com

Financiamiento: Ninguno.

Conflicto de intereses: Ninguno que declarar.

Recibido: 1-4-2016

Aceptado: 21-6-2016
We reporta 2 year old boy with X-linked agammaglobulinemia, with no history of interest, who presented with $P$. aeruginosa sepsis. He had an excellent clinical improvement without further important infections after intravenous immunoglobulin replacement therapy.

Key words: X-linked agammaglobulinemia, immunoglobulins, ecthyma, gangrene, P. aeruginosa.

http:/ /dx.doi.org/10.5546/aap.2016.e444

\section{INTRODUCCIÓN}

La agammaglobulinemia ligada al X (X-linked agammaglobulinemia; XLA, por sus siglas en inglés) es una inmunodeficiencia humoral primaria, recesiva y ligada al cromosoma $X$, en la que existe un bloqueo en la diferenciación del linfocito pro-B al pre-B por una alteración en una proteína de transducción de señales, la tirosin kinasa de Bruton (Bruton's tyrosine kinase; Btk, por sus siglas en inglés). De esta forma, presenta disminución marcada de linfocitos B maduros (menos del 2\% del total), hipo-/agammaglobulinemia (cifras de inmunoglobulinas G, A y M por debajo de 2 desviaciones estándar) y escasa o nula respuesta humoral a las inmunizaciones..$^{1-4}$

Los defectos en la Btk, consecuencia de mutaciones a nivel del brazo largo del cromosoma X (Xq21.2-Xq22.2), representan la causa más frecuente de agammaglobulinemia congénita (el $85 \%$ de los casos). ${ }^{1-3}$

Se caracteriza por infecciones graves, recurrentes y difíciles de tratar de etiología bacteriana (con mayor frecuencia, por bacterias encapsuladas), así como vírica por enterovirus o causadas por microorganismos oportunistas, que comienzan a los 6 meses. La única característica física es la ausencia o disminución del tamaño de las amígdalas y los ganglios linfáticos, que se observa en la mayoría de los pacientes. ${ }^{1-3}$

Las infecciones se producen, con mayor frecuencia, en la superficie de las membranas mucosas o en zonas próximas, como el oído medio, los senos paranasales y los pulmones. Son frecuentes las otitis, las conjuntivitis, las infecciones sinopulmonares crónicas y las bronquitis. Son menos comunes los cuadros 
de diarrea crónica por el parásito Giardia, meningoencefalitis por enterovirus, artritis o sepsis por $P$. aeruginosa. ${ }^{1-3}$

Los microorganismos que con más frecuencia producen estas infecciones son neumococo, $H$. influenzae tipo b, S. aureus, S. pyogenes, P. aeruginosa, Campylobacter spp., Mycoplasma spp. enterovirus y G. lamblia. ${ }^{1-3}$

La infección por $P$. aeruginosa es frecuente en pacientes inmunocomprometidos. La sepsis por dicha bacteria no difiere clínicamente de la producida por otra bacteria Gram-negativa, pero pueden existir rasgos diferenciales, como el desarrollo del ectima gangrenoso, una lesión a nivel celular resultado de la invasión bacteriana perivascular, con la consiguiente isquemia y necrosis de la zona. Otras alteraciones de la piel incluyen exantema maculopapular difuso, aparición de vesículas o pústulas, áreas de celulitis y abscesos metastásicos. ${ }^{6,7}$

\section{CUADRO CLÍNICO}

Paciente varón de 2 años de edad sin antecedentes personales ni relevantes. Ingresó a la Unidad de Cuidados Intensivos con enfermedad de 24 horas de evolución y diagnóstico probable de sepsis. Al momento del examen físico, presentó regular estado general, fiebre, inestabilidad hemodinámica, múltiples lesiones papuloeritematosas en las extremidades inferiores compatibles con picaduras, exantema maculopapular, que desapareció con la vitropresión, y lesión vesiculosa en el hemiescroto derecho, que, inicialmente, fue maculosa (Figura 1).

De los exámenes complementarios solicitados al ingresar, se destacó un recuento de glóbulos blancos de $1940 / \mathrm{mm}^{3}$ asociado a neutropenia grave $\left(0 / \mathrm{mm}^{3}\right)$; proteína $C$ reactiva (PCR): $12,73 \mathrm{mg} / \mathrm{dl}$; procalcitonina: $56,39 \mathrm{ng} / \mathrm{ml}$; actividad de protrombina: $47 \%$. Se inició antibioterapia intravenosa y, a las 24 horas, el hemocultivo se informó positivo para Pseudomona aeruginosa.

Luego, se mantuvo hemodinámicamente estable, sin requerir apoyo inotrópico ni asistencia ventilatoria mecánica. Presentó mejoría del estado general y permaneció afebril. La lesión escrotal, compatible con ectima gangrenoso, evolucionó a costra y requirió cierre quirúrgico. Presentó un absceso, que necesitó un drenaje en la base del quinto dedo del pie (cultivo positivo para $P$. aeruginosa) (Figura 2), fístula perianal y lesiones maculares en las extremidades inferiores,
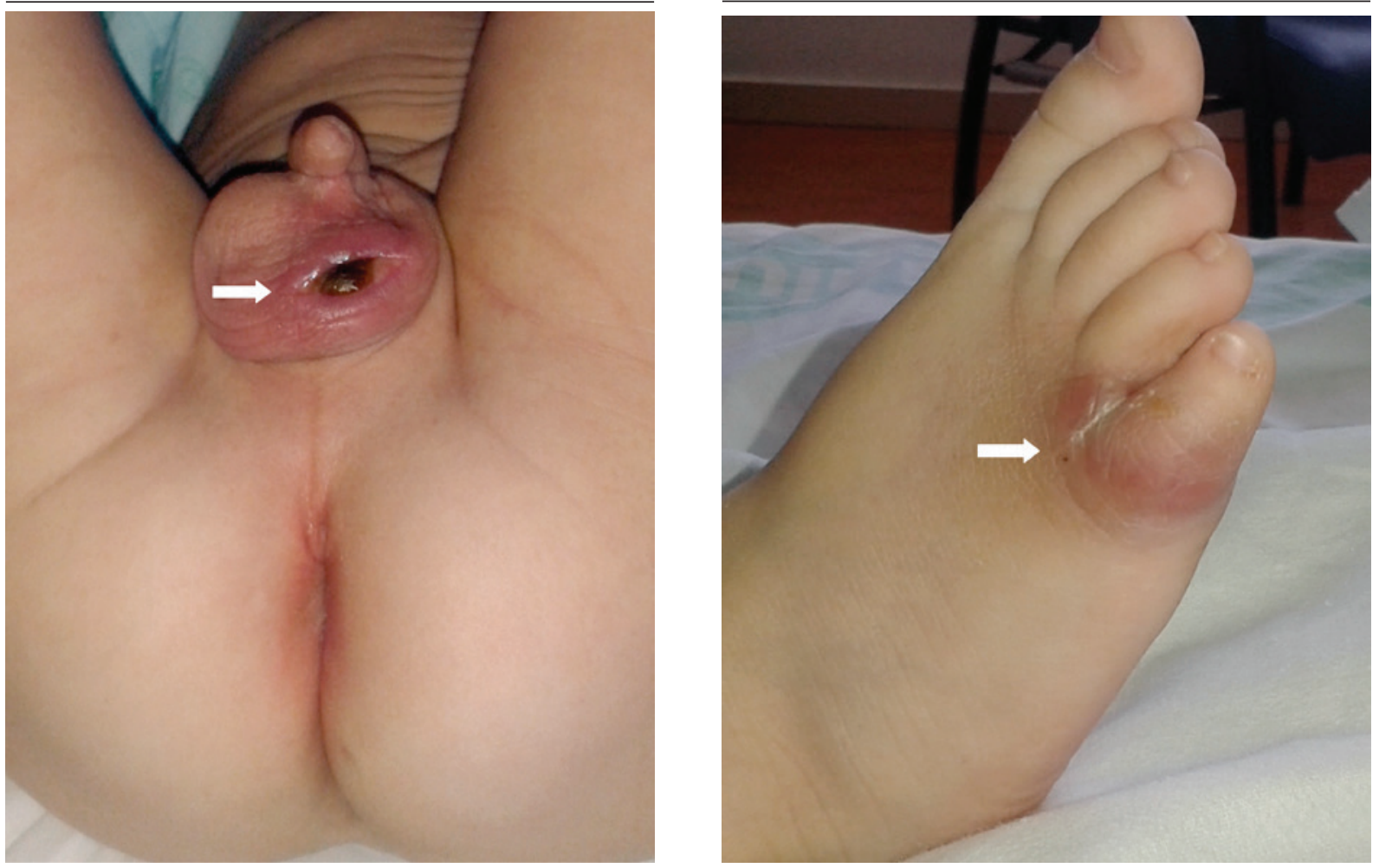
que evolucionaron a nódulos e involucionaron sin llegar a drenar (Figura 3). La neutropenia se solucionó tras la resolución de la infección.

Se realizó una gammagrafía ósea, que descartó osteomielitis. Dado el aislamiento de un patógeno poco frecuente, se realizó un estudio inmune, en el que se destacaron linfocitos $\left(4820 / \mathrm{mm}^{3}\right.$; linfocitos B: $0,25 \%$ ) e inmunoglobulinas (A: $<6,67 \mathrm{mg} / \mathrm{dl}$; G: 96,4 mg/dl; M: 28,4 mg/dl). Las serologías para Rickettsia conorii IgG, citomegalovirus IgM, virus de la hepatitis $C$, virus de la hepatitis $B$, virus de la hepatitis A, rubéola IgG, sarampión IgG, parotiditis IgG, varicela-zóster IgG, virus del herpes IgG/IgM, parvovirus B19 IgG/IgM fueron negativas.

Tras conocer el diagnóstico de agammaglobulinemia, se comprobó que el tejido amigdalar estaba presente con tamaño y estructura normales.

Con los resultados obtenidos, se realizó el diagnóstico de XLA, se inició el tratamiento con IgG intravenosa y se mantuvieron valores de IgG residual $>700 \mathrm{mg} / \mathrm{dl}$ tras el alta, mediante su administración de forma mensual.

FIGURA 3. Lesión nodular en la extremidad inferior izquierda

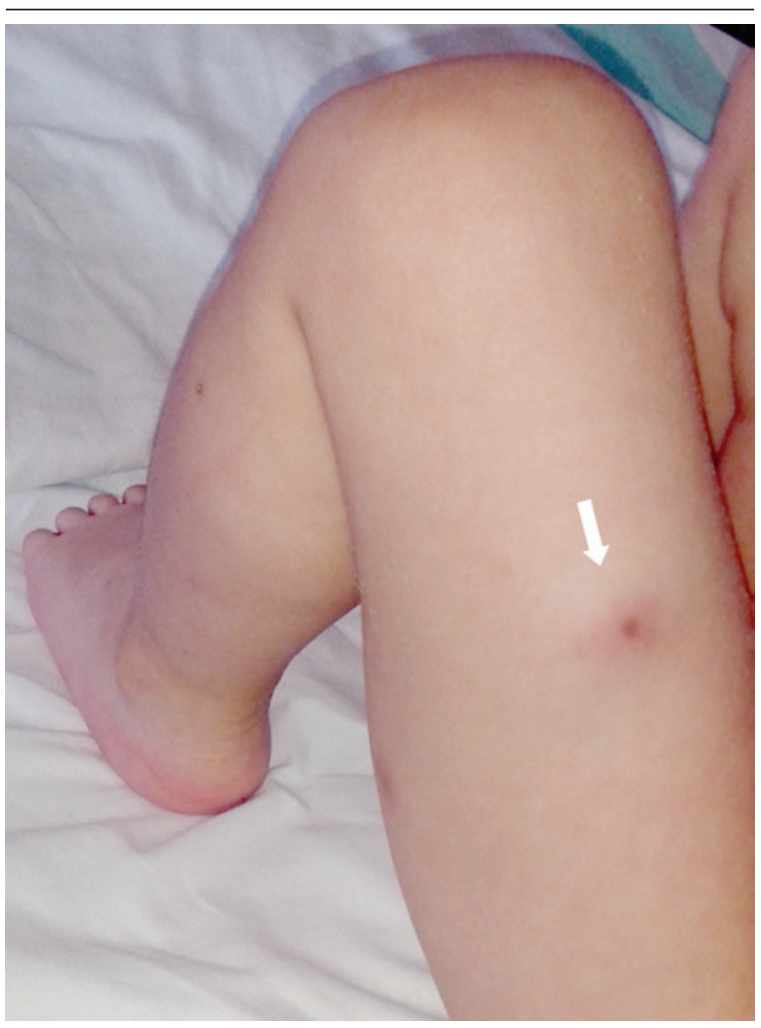

El estudio molecular del gen de la Btk demostró una alteración en el exón 14 del gen "c1185_1189 del GGAAAinsTTG" compatible con mutación, que no fue encontrada en el estudio molecular realizado a la madre del paciente.

\section{DISCUSIÓN}

La sospecha de XLA es, en la mayoría de los casos, orientada por los antecedentes familiares, pero estos pueden no estar presentes en el interrogatorio. Su diagnóstico es relativamente sencillo cuando existen dichos antecedentes, pero, en un tercio de los casos, no se dan y debe existir una confirmación molecular del defecto en el gen o de su expresión (mediante el análisis del ácido desoxirribonucleico -ADN-, ácido ribonucleico mensajero -ARNm- o análisis proteico), teniendo en cuenta que las mutaciones encontradas en dicho gen son muy heterogéneas, por lo general, particulares para cada familia. ${ }^{1-3}$

La mayoría de los pacientes comienzan a tener síntomas a los 6 meses, cuando desaparecen las inmunoglobulinas maternas, aunque, en función de los síntomas presentes, el intervalo diagnóstico puede ser muy amplio, hasta los 18-20 meses.

En nuestro paciente, la ausencia de infecciones piógenas recurrentes dentro de sus antecedentes, así como la ausencia de antecedentes familiares, no permitió anticipar el diagnóstico.

En cuanto al manejo de la enfermedad, se basa en la terapia sustitutiva con IgG, que puede ser, principalmente, por dos vías: intravenosa (cada 21-28 días) o subcutánea (cada 7-15 días), con el objetivo de mantener niveles séricos por encima de $500-700 \mathrm{mg} / \mathrm{dl}$ y conseguir un adecuado control de las infecciones. La mayoría de los pacientes con XLA que reciben IgG supletoria en dosis mayor de $600 \mathrm{mg} / \mathrm{kg}$ o igual y tiempo adecuado podrán realizar sus actividades habituales, sin ser necesario aislarlos ni limitarlas. Los niños con XLA pueden participar en todas las actividades escolares y extracurriculares habituales. ${ }^{1-3}$

Otras consideraciones importantes incluyen el tratamiento antibiótico de amplio espectro ante cualquier infección documentada y/o sospechada, ${ }^{1-3}$ así como evitar las vacunas de virus/bacterias vivos tanto en los pacientes como en sus familiares. Las vacunas inactivadas son seguras y están recomendadas en estos pacientes. A pesar de producir deficiente o nula respuesta humoral, son capaces de inducir respuestas celulares que pueden resultar parcialmente protectoras. ${ }^{4}$ 
Es preciso señalar que las infecciones invasoras por $P$. aeruginosa, por lo general, se van a producir con más frecuencia en el ambiente hospitalario y en pacientes con enfermedades de base: inmunodeficiencias, fibrosis quística, neoplasias, grandes quemados, prematuridad, patología crónica y tratamientos crónicos con corticoides. Así mismo, los pacientes con neutropenia congénita o adquirida también presentan dicha complicación con mayor frecuencia.

En conclusión, ante un caso de infecciones recurrentes, difíciles de tratar o causadas por microorganismos oportunistas o poco habituales, como Pseudomona, es preciso descartar una inmunodeficiencia primaria asociada.

\section{REFERENCIAS}

1. International Patient Organisation for Primary Inmunodeficiencies. Agammaglobulinemia ligada al cromosoma X [Internet]. [Acceso: 10 de mayo de 2015]. Disponible en: http://www.ipopi.org/uploads/ media/publication / AGAMMAGLOBULINEMIA $\% 20$ LIGADA\%20AL\%20CROMOSOMA\%20X_06.02.08.pdf.

2. Winkelstein JA. Agammaglobulinemia. Waltham: UpToDate; 2014. [Acceso: 10 de mayo de 2015]. Disponible en: http://www-uptodate-com.proxy1.athensams.net/ contents /agammaglobulinemia?source=search_result\&s earch=Agammaglobulinemia\&selectedTitle $=1 \sim 57$.
3. Bonilla FA. Primary humoral immunodeficiencies: an overview. Waltham: UpToDate; 2015. [Acceso: 10 de mayo de 2015]. Disponible en: http://www-uptodatecom.proxy1.athensams.net/contents/primary-humoralimmunodeficiencies-an-overview? source=search_result \&search=Agammaglobulinemia\&selectedTitle $=2 \sim 57$.

4. Mellado Peña MJ, Moreno-Pérez D, Ruíz Contreras J, Hernández-Sampelayo Matos T, et al. Documento de consenso de la Sociedad Española de Infectología Pediátrica y el Comité Asesor de Vacunas de la Asociación Española de Pediatría para la vacunación en inmunodeprimidos. An Pediatr (Barc) 2011;75(6):413.e1-e22.

5. Ruíz Contreras J, González Granado LI. Pruebas de laboratorio en el diagnóstico de las inmunodeficiencias primarias. An Pediatr Contin 2013;11(5):282-90.

6. Kanj SS, Sexton DJ. Pseudomonas aeruginosa bacteremia and endocarditis. Waltham: UpToDate; 2014. [Acceso: 23 de junio de 2016]. Disponible en: http:/ /www.uptodate. com/contents/pseudomonas-aeruginosa-bacteremia-andendocarditis.

7. Kanj SS, Sexton DJ. Pseudomonas aeruginosa skin, soft tissue, and bone infections. Waltham: UpToDate; 2015. [Acceso: 23 de junio de 2016]. Disponible en: http:/ / www. uptodate.com/contents/pseudomonas-aeruginosa-skinsoft-tissue-and-bone-infections.

8. O'Keefe AW, Halbrich M, Ben-Shoshan M, McCusker C. Primary immunodeficiency for the primary care provider. Paediatr Child Health 2016;21(2):e10-4. 